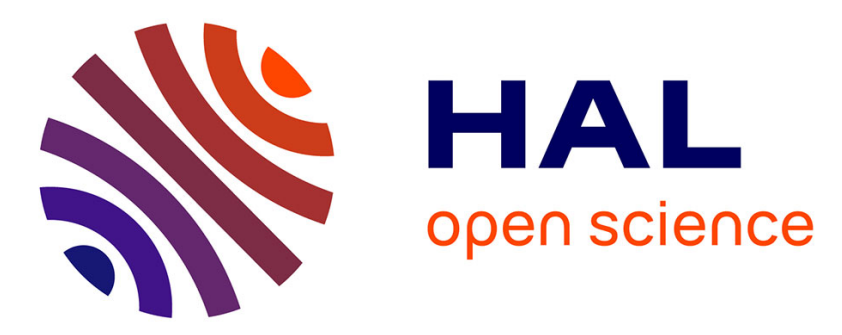

\title{
Water absorption of recycled aggregates: Measurements, influence of temperature and practical consequences
}

Florian Théréné, Emmanuel Keita, Jennifer Nael-Redolfi, Pascal Boustingorry, Laurent Bonafous, Nicolas Roussel

\section{- To cite this version:}

Florian Théréné, Emmanuel Keita, Jennifer Nael-Redolfi, Pascal Boustingorry, Laurent Bonafous, et al.. Water absorption of recycled aggregates: Measurements, influence of temperature and practical consequences. Cement and Concrete Research, 2020, 137, pp.106196. 10.1016/j.cemconres.2020.106196 . hal-02931755

\section{HAL Id: hal-02931755 \\ https://hal.science/hal-02931755}

Submitted on 7 Sep 2020

HAL is a multi-disciplinary open access archive for the deposit and dissemination of scientific research documents, whether they are published or not. The documents may come from teaching and research institutions in France or abroad, or from public or private research centers.
L'archive ouverte pluridisciplinaire HAL, est destinée au dépôt et à la diffusion de documents scientifiques de niveau recherche, publiés ou non, émanant des établissements d'enseignement et de recherche français ou étrangers, des laboratoires publics ou privés. 
$1 \quad$ Published as : Cement and Concrete Research 137 (2020) 106196

\title{
Water Absorption of recycled aggregates: measurements, influence of temperature and practical consequences
}

Florian Théréné, Emmanuel Keita*, Jennifer Naël-Redolfi, Pascal Boustingorry, Laurent Bonafous, Nicolas Roussel

E-mail address: emmanuel.keita@univ-eiffel.fr

\begin{abstract}
Recycled Concrete Aggregates are highly porous and may therefore absorb more water than natural aggregates. Several methods allow for the measurement of water absorption requiring drying at temperature above ambient conditions. We show here that, for temperatures above the ambient temperature $\left(>30^{\circ} \mathrm{C}\right)$ and at low relative humidity, the drying of recycled aggregates removes some bounded water contained in hardened cement paste and increases both measured porosity and water absorption. Porosity and XRD suggest that porosity increases due to ettringite dehydration. Thus, the drying step required to characterize recycled aggregates leads to a systematic overestimation of the water absorption. Moreover, this overestimation induces an error in mix-design leading to a higher effective water/cement ratio. If absorption and water content are measured with the same preparation protocol, correction is not needed. We finally propose a correction method for the water absorption measured according to the standard protocol (drying at $\left.105^{\circ} \mathrm{C}\right)$.
\end{abstract}




\section{Introduction}

Due to the limited natural resources, the use of Recycled Concrete Aggregates (RCA) is today a growing practice in the construction industry. These RCA result from the crushing and grinding of demolition wastes from our buildings and our infrastructures. As such, RCA differ from natural rounded aggregates from river in both composition and microstructure and can be seen as a composite granular material made of natural aggregates and hardened cement paste.

Since hardened cement paste is highly porous, RCA have porosity 10 to 20 times higher than the porosity of a natural aggregate; it depends strongly on the volume fraction of cement paste in the aggregate. In contact with water or fresh cement paste, they may therefore absorb more water than natural aggregates. This absorption may affect in turn the properties of concretes prepared with RCA. Depending on the time needed for saturation of these aggregates, this water absorption can be at the origin of a decrease in workability [1-3]. Moreover, by compensating for this water absorbed in the mixdesign, high workability can be generated, which can even lead to concrete segregation. In the hardened state, the concrete is more porous, thus increasing the permeability which increases transfers $[3,4]$. Due to porosity, mechanical strength may decrease compared to natural aggregate concrete $[1,3,5-8]$ and the expected service life based on durability tests was reported to reduce significantly $[9,10]$. Thus, porosity and the associated water absorption seems in most studies to be a key parameter for predicting both casting and service-life behavior of concretes incorporating RCA.

Several methods allow for the measurement of water absorption of aggregates [11]. European standards for characterizing the properties of aggregates define a specific method in NF EN 1097-6 [12]. In this test, the aggregates are initially dried. Then, the amount of water absorbed is measured after 24 hours of immersion in water. The drying of the aggregates must be carried out at $105^{\circ} \mathrm{C}$. However, the standard was designed before the extensive use of recycled aggregates. Indeed, given the presence of hardened 
cement paste in their structure, drying at high temperatures can affect its microstructure and thus modify its water absorption.

Nevertheless, several studies on the absorption of recycled aggregates use a drying protocol based on the above standard with a temperature of $105^{\circ} \mathrm{C}[3,13-15]$. Some studies recommend a reduction of the drying temperature to $70-75^{\circ} \mathrm{C}[3,4,16]$ to limit the alteration of the hardened cement paste. However, it has been shown recently that hydrates like Ettringite are very sensitive to temperature changes above $75^{\circ} \mathrm{C}$ [17-21]. Moreover, Baquerizo et al. [20] showed that water content in Ettringite changes significantly with a small variation of temperature and relative humidity. Thus, for recycled aggregates, the drying protocol should be carefully chosen and the influence of temperature and relative humidity on the water absorption measurements need to be addressed.

In this paper, we show that the drying of recycled aggregates for temperatures above the ambient temperature $\left(>30^{\circ} \mathrm{C}\right)$ and at low relative humidity $(<\mathbf{2 0 \%})$ removes some bounded water contained in hardened cement paste and increases both measured porosity and measured water absorption. By measuring in parallel porosity and chemical composition variations with temperature, we suggest that the increase in porosity finds its origin in ettringite dehydration, which released bound water in an amount similar to the measured water absorption increase. Moreover, this absorption overestimation induces a systematic error in mix-design leading to a higher effective water/cement ratio. We finally propose a correction method to be applied to the water absorption measured according to the standard protocol (drying at $105^{\circ} \mathrm{C}$ ).

\section{Materials and experimental procedures}

\section{1. Materials}

Four CEM I types of cement from four different factories from Lafarge Holcim with specific density around 3.15 were used in this study. These cements were produced in 
four different factories (Saint Vigor (SV); Lägerdorf (L); Le Teil (LT) and Saint Pierre La Cour). Their main difference is in their $\mathrm{C}_{3} \mathrm{~A}$ content. Their chemical composition is given in Table 1. It is obtained through Inductively Coupled Plasma and Atomic Emission Spectrometry (ICP-AES Horiba ultima 2000), analytical technique that allows the quantification of the element traces in liquid solutions by comparison of standard materials (for the cement) and by Differential thermal analysis (ATD-ATG NETZSCH STA 409E). Their mineral composition is also given in Table 1. The W/C of the cement paste in recycled aggregates varies depending on the concrete origin. To study a wide range of recycled aggregates in terms of absorption and with different microstructures, we prepared cement pastes at different water-to-cement ratios (W/C): at $\mathrm{W} / \mathrm{C}=0.5$ with cements SV, L, LT and SPLC; W/C=0.2-0.3-0.4-0.6 with cement L. In the case of $\mathrm{W} / \mathrm{C}=0.2$, it was necessary to use a superplasticizer. We chose a commercial one, CHRYSO ${ }^{\circ}$ Fluid Premia 570 at $1.0 \%$ in weight of cement in order to have a homogeneous and fluid material for samples casting. All cement pastes were mixed for 2 min using a Rayneri mixer at $840 \mathrm{rpm}$. 
104 Chemical and mineral composition of the cement powders

\section{Chemical composition (\% by mass)}

\begin{tabular}{|c|c|c|c|c|c|c|c|c|}
\hline & $\mathrm{CaO}$ & $\mathrm{SiO}_{2}$ & $\mathbf{A l}_{2} \mathbf{O}_{3}$ & $\mathrm{Fe}_{2} \mathrm{O}_{3}$ & MgO & $\mathrm{SO}_{3}$ & Cl & $\begin{array}{c}\text { Ignition } \\
\text { loss }\end{array}$ \\
\hline $\begin{array}{c}\text { Saint Vigor } \\
\text { (SV) }\end{array}$ & $65.4 \%$ & $21.0 \%$ & $3.6 \%$ & $4.4 \%$ & $0.8 \%$ & $2.3 \%$ & $0.1 \%$ & $1.5 \%$ \\
\hline Lägerdorf (L) & $61.9 \%$ & $19.1 \%$ & $3.6 \%$ & $4.2 \%$ & $0.7 \%$ & $2.5 \%$ & $0.1 \%$ & $1.5 \%$ \\
\hline Le Teil (LT) & $68.6 \%$ & $25.1 \%$ & $2.5 \%$ & $0.2 \%$ & $0.5 \%$ & $2.2 \%$ & $0.1 \%$ & $2.6 \%$ \\
\hline Saint Pierre & & & & & & & & $1.2 \%$ \\
\hline La Cour & $66.5 \%$ & $20.9 \%$ & $4.6 \%$ & $2.6 \%$ & $0.9 \%$ & $3.0 \%$ & $0.1 \%$ & \\
\hline \multicolumn{9}{|c|}{ Mineral composition (\% by mass) } \\
\hline & & $\mathrm{C}_{3} \mathrm{~S}$ & $\mathrm{C}_{2} \mathrm{~S}$ & $\mathrm{C}_{3} \mathrm{~A}$ & $\mathrm{C}_{4} \mathrm{AF}$ & Gypsum & $\begin{array}{l}\mathrm{CaO} \\
\text { free }\end{array}$ & Calcite \\
\hline $\begin{array}{c}\text { Saint Vigor } \\
\text { (SV) }\end{array}$ & & $63.2 \%$ & $12.5 \%$ & $2.5 \%$ & $12.6 \%$ & $5.0 \%$ & 0.7 & 1.8 \\
\hline Lägerdorf (L) & & $67.2 \%$ & $5.3 \%$ & $2.5 \%$ & $12.7 \%$ & $5.4 \%$ & 0.8 & 0.5 \\
\hline Le Teil (LT) & & $58.2 \%$ & $25.8 \%$ & $6.2 \%$ & $0.6 \%$ & $4.7 \%$ & 0.8 & 2.6 \\
\hline $\begin{array}{l}\text { Saint Pierre La } \\
\text { Cour (SPLC) }\end{array}$ & & $64.5 \%$ & $11.3 \%$ & $7.8 \%$ & $7.9 \%$ & $6.5 \%$ & 0.4 & 0.6 \\
\hline
\end{tabular}

105

106 After mixing, the cement pastes were poured into $4 \times 4 \times 16 \mathrm{~cm}^{3}$ molds and demolded

107 after 24 hours. The samples were then immersed in water for 3 months to ensure that

108 cement pastes were close to complete hydration. Afterwards, the hardened cement paste

109 samples were crushed using a jaw crusher to obtain aggregates with different sizes. For

110 this study, we sieved the crushed aggregates and only kept the fraction between 6 to 10

$111 \mathrm{~mm}$ in order to ease the measurement of water absorption. Indeed, in the case of smaller 
particles $(<4 \mathrm{~mm})$ and highly angular particles such as recycled sand, water absorption according to the standard method induces a high uncertainty on measurements and therefore requires alternative methods [22,23], which are out of the scope of this study.

\section{2. Water absorption and porosity measurements}

The Water Absorption (WA) is the ratio between the water required to fill a porous sample and its dry mass. The water absorption measurement consists in drying at a specific drying temperature $\left(20^{\circ} \mathrm{C} ; 30^{\circ} \mathrm{C} ; 45^{\circ} \mathrm{C} ; 75^{\circ} \mathrm{C} ; 105^{\circ} \mathrm{C}\right)$ the samples in order to remove all the water present in the pores $\left(\mathrm{M}_{\mathrm{dry}}\right)$. Then, the samples are immersed in water. The solid-to-liquid ratio is of $100 \mathrm{~g}$ for $1 \mathrm{~L}$, water is not flowing during immersion and hardened cement dissolution is quite slow [24], thus we consider that leaching is neglectable. After 24 hours of water immersion, the samples are removed from water. Finally, the aggregate surface is carefully dried with absorbent cloths until the water films on the aggregate surface disappear to obtain the so-called "Saturated Surface Dry" (SSD) mass (MSSD) in accordance with standard NF EN 1097-6 [12]. To assess its reliability, we also measure the SSD mass with an in-house evaporative method [25]. At this stage, the aggregate is saturated but without free water on the surface.

From these two measurements, the water absorption is computed as:

$$
\text { Water absorption }(W A)=\frac{100 \times\left(M_{S S D}-M_{d r y}\right)}{M_{d r y}} \text { (1) }
$$

However, in this study, as we will use different cement pastes with varying water to cement ratio $(\mathrm{W} / \mathrm{C})$, the volume of sample will also vary for the same mass $\mathrm{M}_{\mathrm{dry}}$. To compare samples with different density, the water absorption by volume is more relevant than by mass. Thus, the porosity $\varphi$ (ratio of void to the total volume) is equal to:

$$
\text { Porosity } \varphi=\frac{100 \times\left(M_{S S D}-M_{d r y}\right)}{M_{d r y}} * \rho_{\text {Aggregate }} \text { (2) }
$$

where $\rho_{\text {Aggregate }}$ is the dry density of the cement pastes. This density $\rho_{\text {Aggregate }}$ is equal to the ratio between the dry mass $\mathrm{M}_{\mathrm{dry}}$ of the cement paste and the volume of the sample (taking into account the presence of pores), corresponding to the difference between the $\mathrm{M}_{\mathrm{SSD}}$ and the mass of the sample immersed in water (measured by hydrostatic weighing 
in accordance with standard NF P18-459 [26]).

Since we use various drying temperatures in this study, we had to choose a criterion defining the end of drying (i.e. when all water has evaporated). In this study, we therefore consider that drying is over when the mass loss between two successive weightings at 24 -hour intervals is less than $0.05 \%$. As the drying time can be very long, for instance, one month in the case of drying at $30^{\circ} \mathrm{C}$, soda lime aggregates are present in the drying chamber to avoid carbonation. After treatment, the aggregates were stored at $20^{\circ} \mathrm{C}$ and relative humidity of $6 \%$, also to limit carbonation.

\section{3. Mercury Intrusion Porosimetry}

Mercury Intrusion Porosimetry characterizes the structure and the interconnected pores of porous material $[27,28]$. The mercury intrusion porosimeter used in this study is Autopore IV with maximum and minimum applied pressures of $400 \mathrm{MPa}$ and $0.01 \mathrm{kPa}$, allowing to characterize pore sizes from $5 \mathrm{~nm}$ to $60 \mu \mathrm{m}$. To estimate this pore size, we consider a contact angle $\theta_{\mathrm{Hg}}=141^{\circ}$. The measurement parameters used for this study are $0.0035 \mathrm{MPa}$ for the initial mercury pressure with an exponential mercury pressure increment until $20 \mathrm{MPa}$ and an equilibrium time for each data point of 10 seconds. The sample mass for each test is between 1.0 to 1.5 grams (approximately equal to 2 or 3 $6 / 10 \mathrm{~mm}$ aggregates). Three different temperatures were used $\left(30-75-105^{\circ} \mathrm{C}\right)$ to dry the samples before testing.

\section{4. X-ray diffraction}

The XRD experiments were carried out in a Diffractometer D8 Advance from Bruker with a Cobalt anode under $35 \mathrm{~mA} / 40 \mathrm{kV}$ without monochromator. We measured the diffraction angles between 3 to $80^{\circ}$ with an angle increment equal to $0.01^{\circ}$ and an acquisition time of 1 second.

To carry out X-Ray diffraction, samples of hardened cement pastes (2- 3 grams) were manually ground (in order to avoid heating the sample during grinding) until samples with a size of less than $63 \mu \mathrm{m}$ were obtained.

The processing of the obtained diffractograms was performed with the Eva software 
coupled to the mineralogical database ICDDPdf2 to determine the presence of crystalline phases typical of a cement paste. Furthermore, to compare their proportion of crystalline phases (Portlandite, Ettringite) quantitatively, the TOPAS software from Bruker was used for quantification by the Rietveld method. The results of Rietveld analyses give the mass percentages of the crystalline phases present in the diffractograms. By knowing the density of each hydrate [27], we then computed the volume fraction of each component.

\section{Experimental results}

\section{1. Water absorption measurements as a function of drying}

\section{temperature for hardened cement pastes $(\mathrm{W} / \mathrm{C}=\mathbf{0 . 5})$}

In order to evaluate the influence of the drying temperature on water absorption of hardened cement paste, different temperatures were used to prepare the samples before the water absorption measurements.

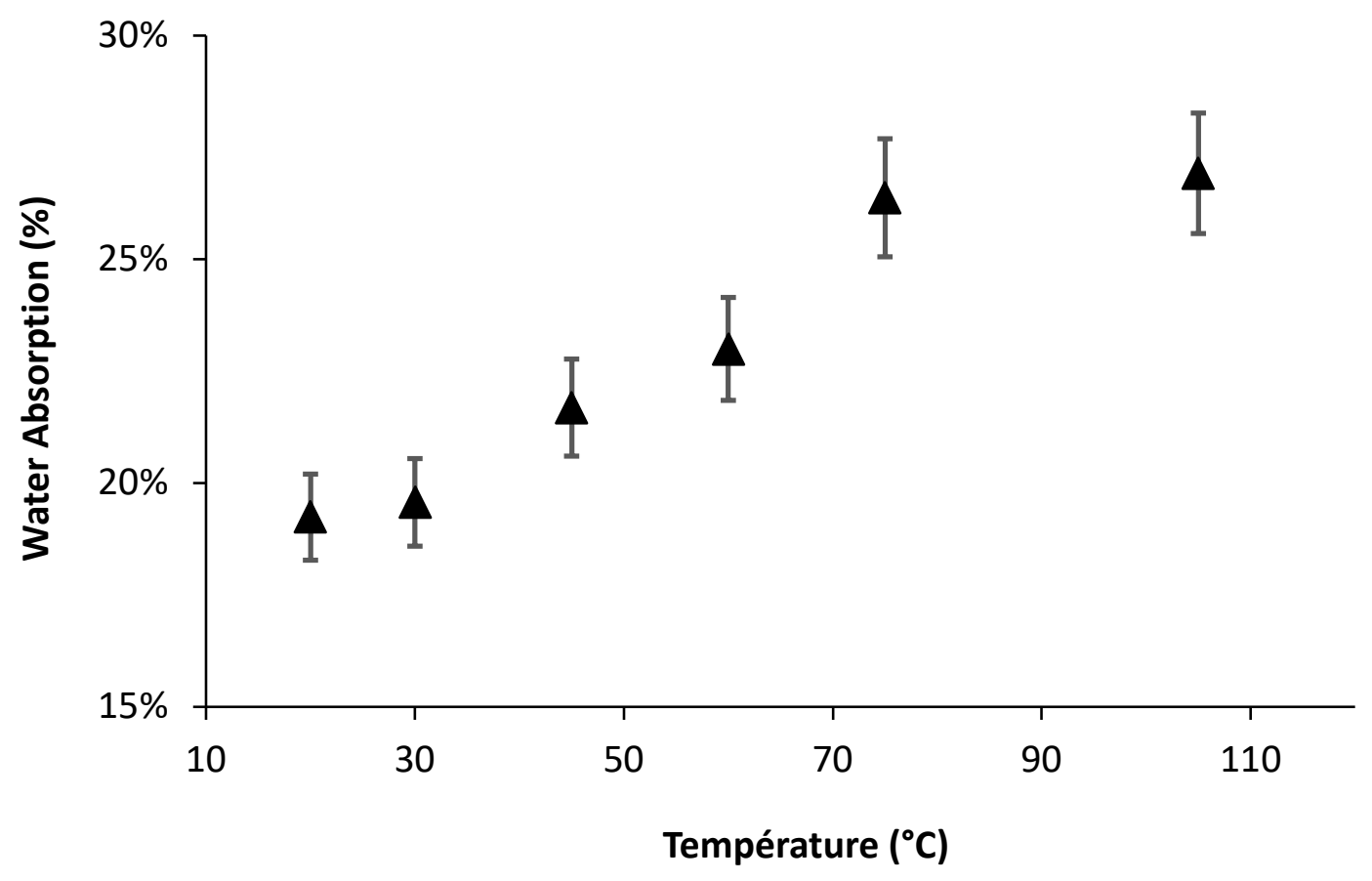

Fig. 1. Water absorption of hardened cement paste (W/C 0.5 - cement SV) as a function of the drying temperature. 
We plot in Fig. 1 the water absorption measurements obtained on a hardened cement paste as a function of the drying temperature applied to the samples before the water absorption measurement. It can be seen that water absorption increases with drying temperature. Indeed, we note a linear increase in water absorption between 30 and $75^{\circ} \mathrm{C}$. While the absorption measured after drying at 20 or $30{ }^{\circ} \mathrm{C}$ is similar, the water absorption measured after drying at $75^{\circ} \mathrm{C}$ is $40 \%$ higher than the drying at $20 / 30^{\circ} \mathrm{C}$. The water absorption measured after drying at $105^{\circ} \mathrm{C}$ is the same as the one measured after drying at $75^{\circ} \mathrm{C}$.

\section{2. Pore size distribution as a function of drying temperature for} hardened cement pastes $(\mathrm{W} / \mathrm{C}=\mathbf{0 . 5})$

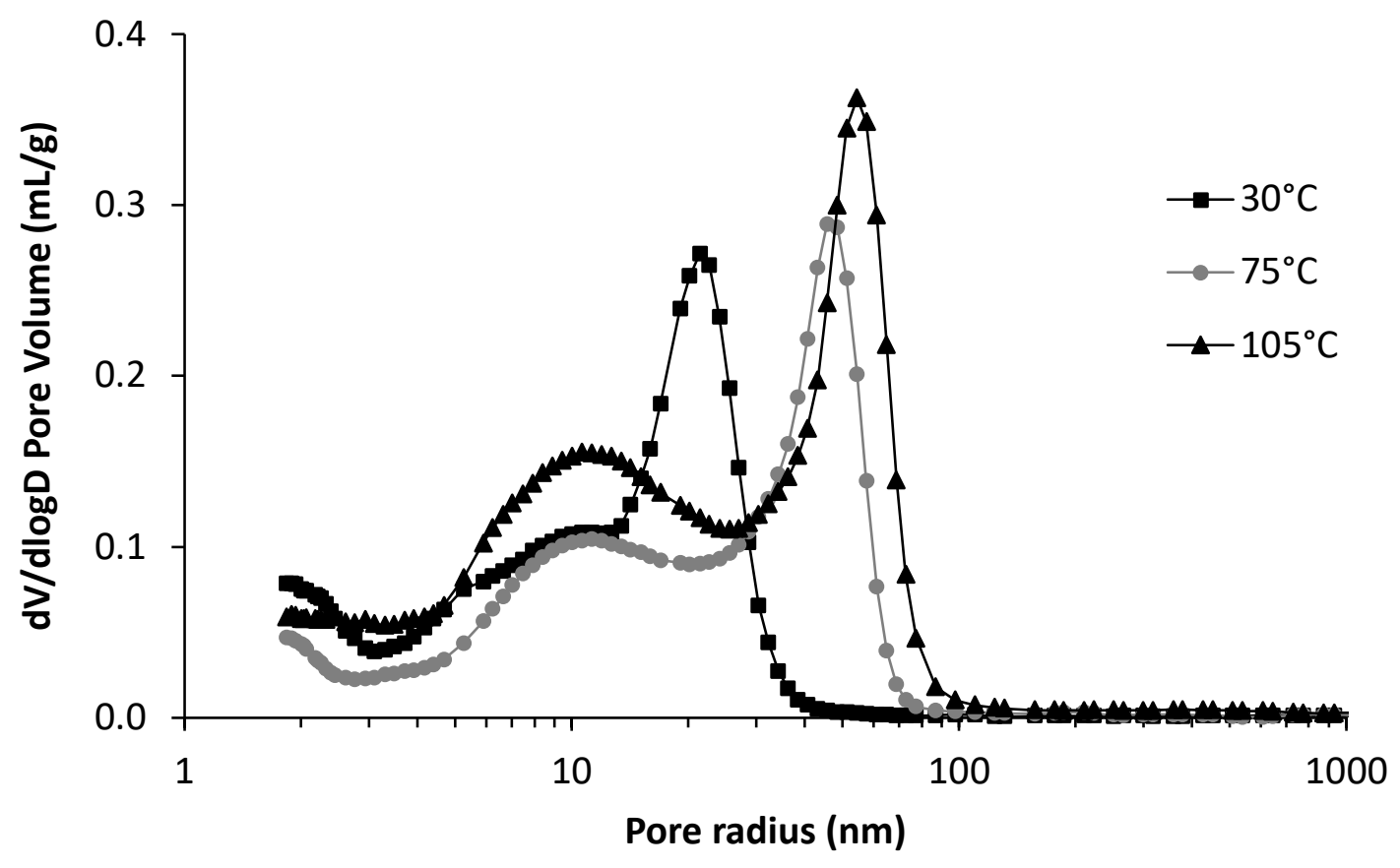

Fig. 2. Pore size distribution of hardened cement paste (W/C 0.5 - cement SV) obtained by mercury intrusion porosimetry (MIP) after drying at 30,75 and $105^{\circ} \mathrm{C}$.

We observed the porous distribution of a W/C 0.5 hardened cement using mercury intrusion porosimetry for drying temperatures of 30,75 and $105^{\circ} \mathrm{C}$. The pore size distribution for 75 and $105^{\circ} \mathrm{C}$ is similar and two pore populations are visible, a first population at $50 \mathrm{~nm}$ and the second around $12 \mathrm{~nm}$ (see Fig. 2). On the contrary, in the 
case of drying at $30^{\circ} \mathrm{C}$, most of the pores are around $10-20 \mathrm{~nm}$.

Thereby, the maximum pore size of dried cement pastes increases with the drying temperature. Indeed, the maximum pore radius of the sample for drying at $105^{\circ} \mathrm{C}$ is 55 $\mathrm{nm}$, versus $23 \mathrm{~nm}$ for the drying at $30^{\circ} \mathrm{C}$. Moreover, the total porosity measured by MIP increases sharply with the drying temperature: at $105^{\circ} \mathrm{C}$, the porosity is $32 \%$ compared to $25 \%$ at $30^{\circ} \mathrm{C}$. Therefore, drying at $105^{\circ} \mathrm{C}$ has the effect of increasing the porosity of the cement paste and also roughly doubling the pore size of the cement paste compared to drying at $30^{\circ} \mathrm{C}$.

\section{3. Reversibility of porosity increase $(W / C=0.5)$}

In order to better understand the impact of drying on water absorption, a specific drying sequence was tested. It consists of first drying the cement paste at $105^{\circ} \mathrm{C}$ and then soaking it in water to measure its water absorption. Following this first step, the sample is dried at $30^{\circ} \mathrm{C}$. As soon as the mass loss is stabilized, the sample is soaked in water a second time and its water absorption is measured.

We compare the water absorption results measured for samples that have undergone the specific drying sequence with the reference, corresponding to water absorption in hardened cement pastes directly dried at $30^{\circ} \mathrm{C}$.

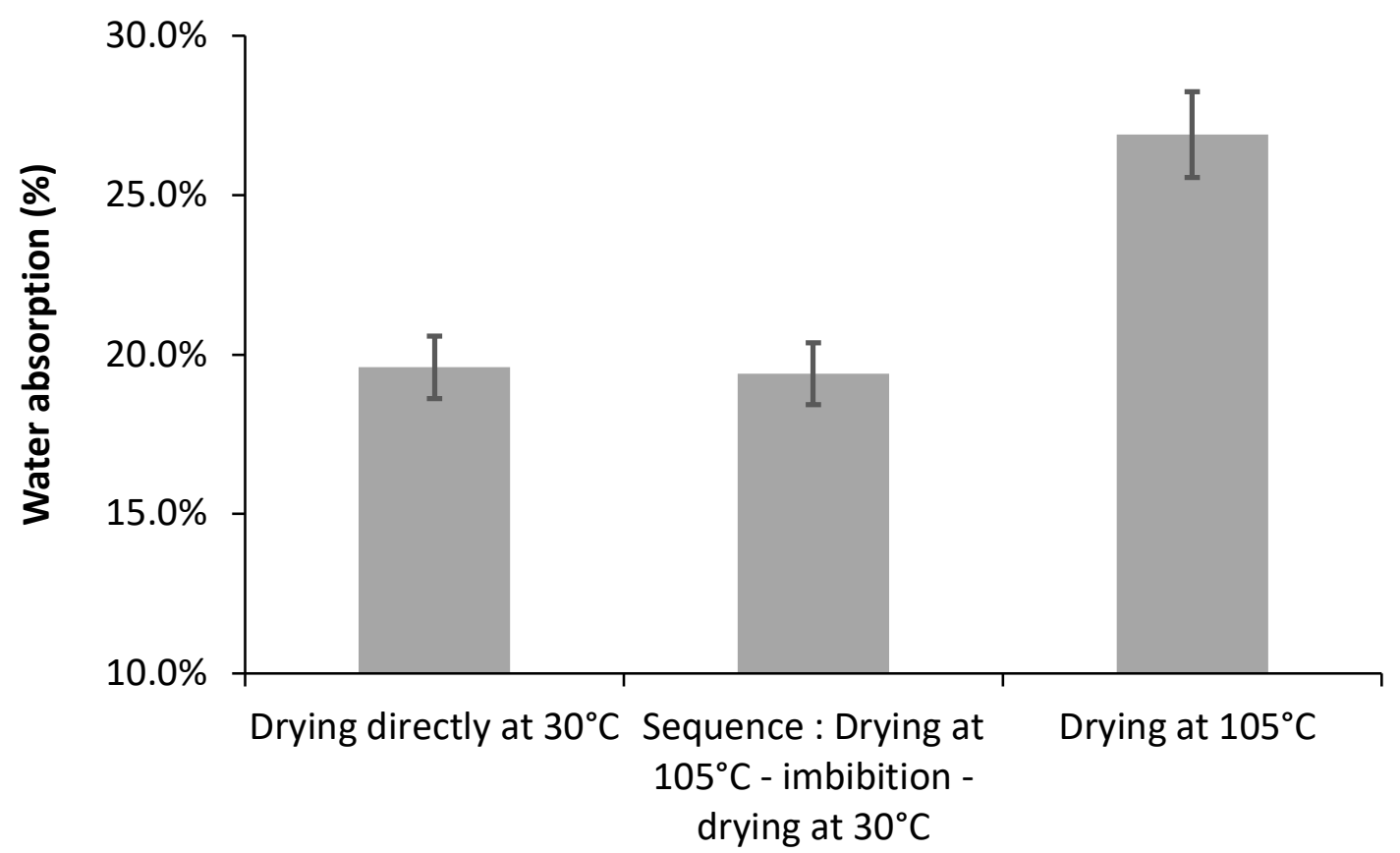


226 Fig. 3. Water absorption for samples with different drying history

227

228 The water absorption of the hardened cement paste that underwent the specific drying 229 sequence is identical to that of the reference (19\%) (see Fig. 3). Thus, for the 230 investigated samples and conditions (drying at $105^{\circ} \mathrm{C}$ ), the high absorption was not a 231 permanent feature and, after a re-imbibition in water and drying at $30^{\circ} \mathrm{C}$, absorption is 232 identical to the one measured on aggregates that were directly dried at $30^{\circ} \mathrm{C}$. Therefore, 233 we observe an apparently reversible increase in absorption after drying at $105^{\circ} \mathrm{C}$. 

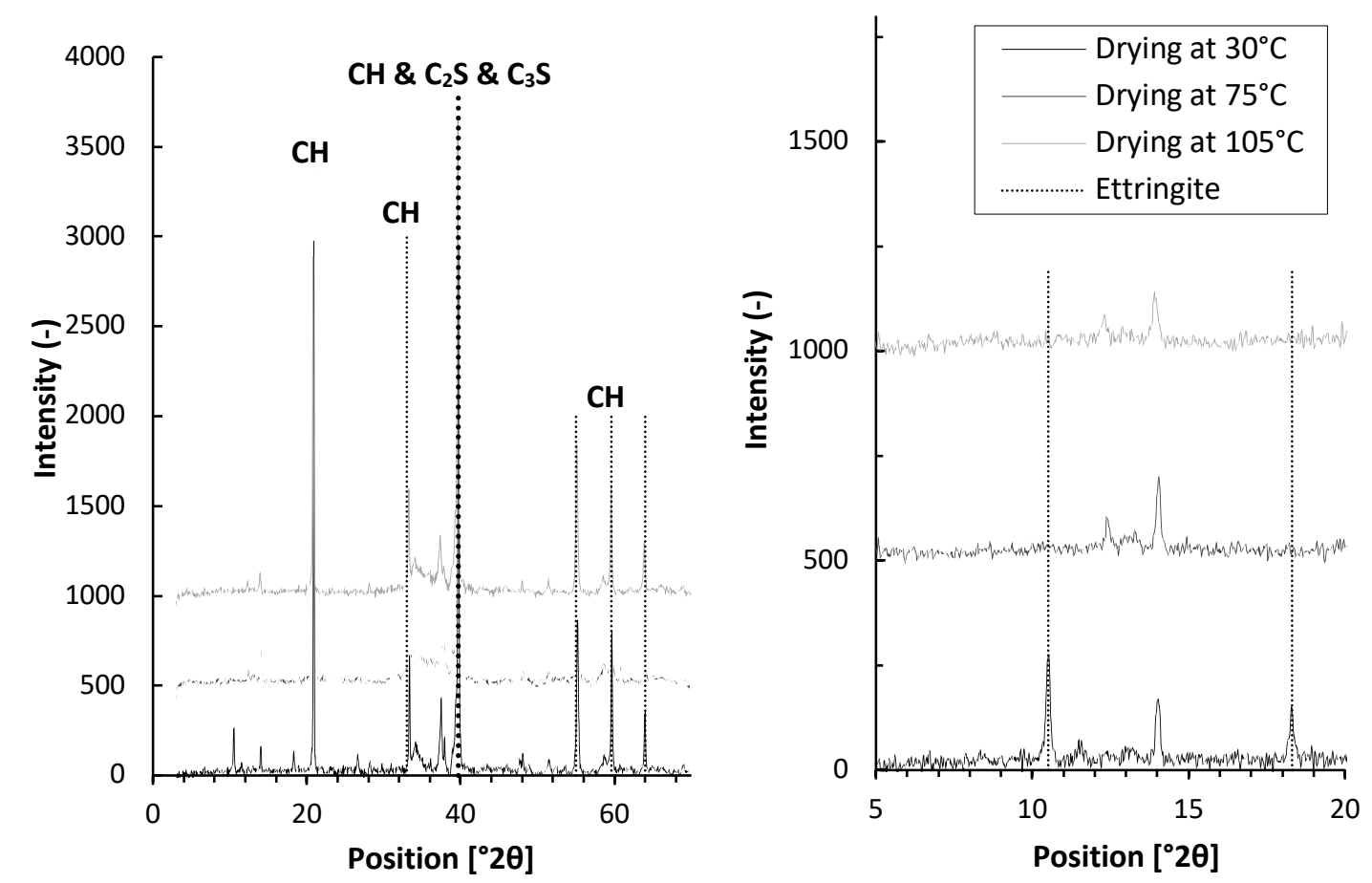

Fig. 4. X-Ray diffractograms of hardened cement paste (W/C 0.5 - cement SV) at different drying temperatures. a) Diffractograms between 0 and $70^{\circ}$ b) Zoom between 7 to $20^{\circ}$

In the diffractograms obtained by XRD measurements of a hardened cement paste, we see the same main characteristic peaks, whatever the drying temperature (see Fig. 4a). Indeed, the peaks of the main hydrates such as Portlandite " $\mathrm{CH}$ " $\left(21^{\circ}, 33^{\circ}, 40^{\circ}, 55^{\circ}\right.$, $\left.60^{\circ}, 64^{\circ}\right)$ or clinker components " $\mathrm{C}_{2} \mathrm{~S} \& \mathrm{C}_{3} \mathrm{~S}$ ” $\left(33-40^{\circ}\right)$ are present.

However, by focusing on small diffraction angles between 7 and $23^{\circ}$, we can observe differences in the diffractograms according to the drying temperature. Indeed, in the case of $30^{\circ} \mathrm{C}$, the characteristic peaks of Ettringite $\left(11\right.$ and $\left.18^{\circ}\right)$ are found. On the contrary, for a drying temperature of 75 and $105^{\circ} \mathrm{C}$, these peaks are no longer present (see Fig. 4b). These results indicate that the disappearance of Ettringite peaks occurs between 30 and $75^{\circ} \mathrm{C}$, which is confirmed by quantification of the fraction of Ettringite. By using the Rietveld method and knowing the density of all the hydrates in the cement paste, we estimated the volume content of crystalline phase hydrates. We obtained a 
volume fraction of $9.5 \pm 2.6 \%$ of Ettringite (measure consistent with state of the art $[27,29,30])$ when drying was performed at $30^{\circ} \mathrm{C}$ against $0.1 \pm 0.1 \%$ for 75 and $105^{\circ} \mathrm{C}$.

\section{5. Influence of the $\mathrm{W} / \mathrm{C}$ ratio}

\section{5. 1. Water absorption}

In previous sections, the water to cement ratio was kept constant at 0.5 . In this section, hardened cement pastes with W/C varying from 0.2 to 0.6 (cement L) were dried at 30 and $105^{\circ} \mathrm{C}$, and their water absorption was measured.

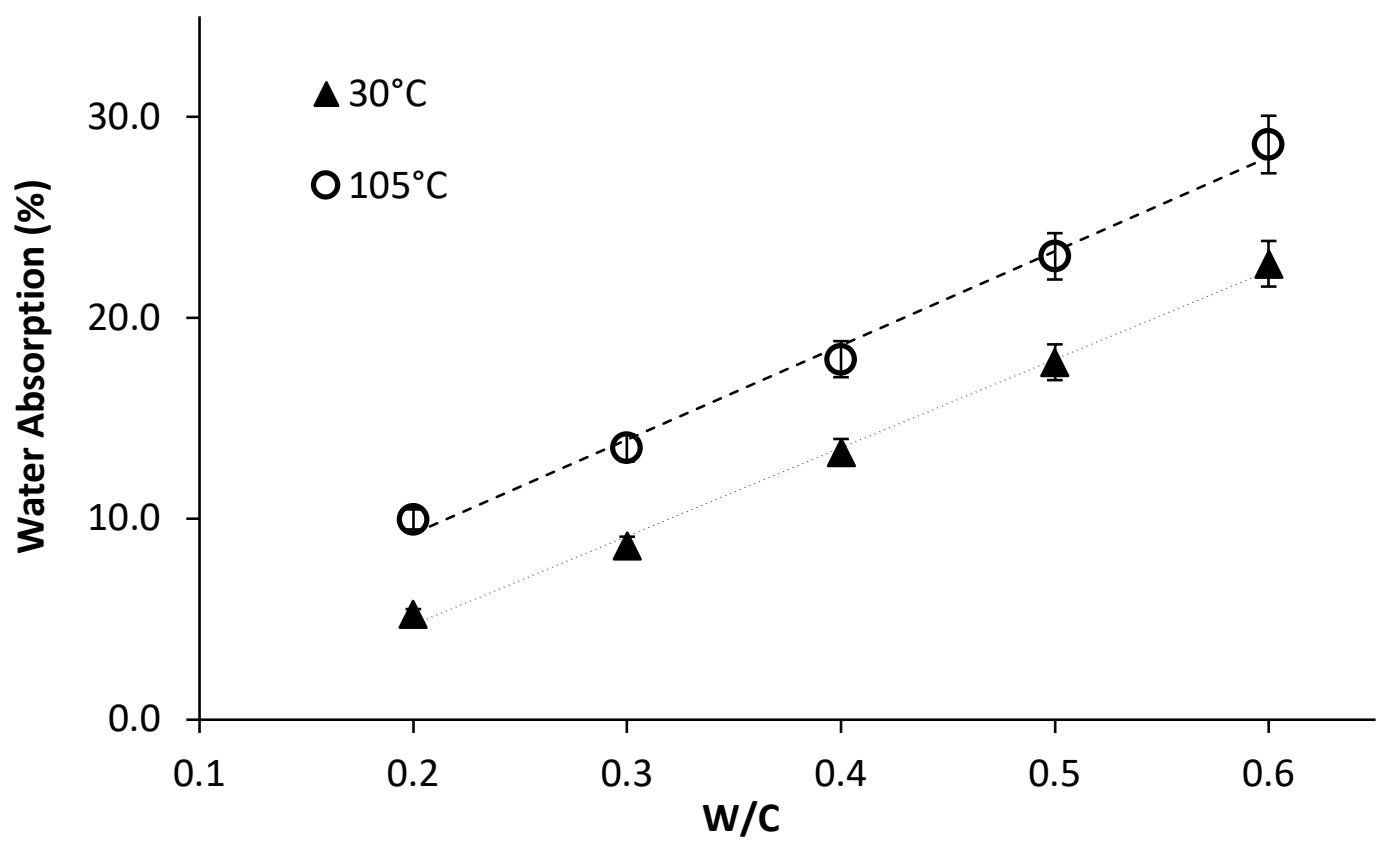

Fig. 5. Comparison of water absorption measured at 30 and $105^{\circ} \mathrm{C}$ for cement pastes at different $\mathrm{W} / \mathrm{C}$ ratios (0.2-0.3-0.4-0.5-0.6 - cement $\mathrm{L})$.

When drying at $30^{\circ} \mathrm{C}$ and $105^{\circ} \mathrm{C}$, water absorption increases linearly with the $\mathrm{W} / \mathrm{C}$ ratio of the cement paste (see Fig. 5). As expected, the higher the W/C ratio of the cement paste, the more porous the aggregate. Moreover, we observe that whatever the $\mathrm{W} / \mathrm{C}$ ratio of the cement paste, the water absorption measured at $105^{\circ} \mathrm{C}$ was always higher than at $30^{\circ} \mathrm{C}$ but follows the same trend along with a parallel linear trend. The difference in water absorption between the two drying temperatures was therefore constant and of the order of $5 \%$. 


\section{5. 2. Ettringite content}

274 X-ray diffraction tests were carried out for all cement pastes, with the two drying 275 temperatures. Based on the results of section 3.3, we focused on the volume content of 276 Ettringite estimated by the Rietveld method for 30 and $105^{\circ} \mathrm{C}$ as a function of the W/C 277 ratio of the cement pastes (see Fig. 6).

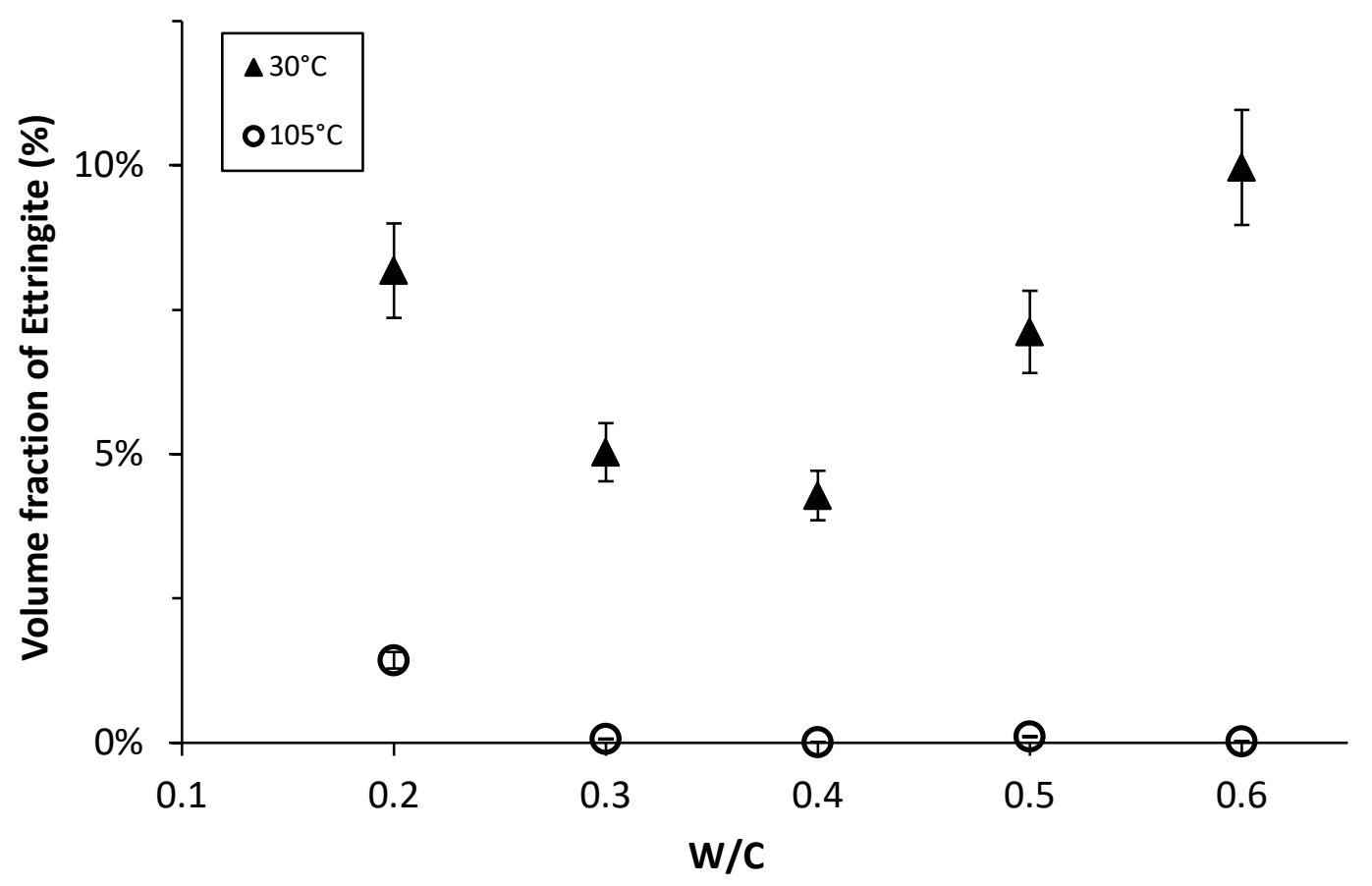

278

Fig. 6. Volume fraction of Ettringite obtained by XRD measurements based on Rietveld method for cement pastes at different $\mathrm{W} / \mathrm{C}$ (cement $\mathrm{L}$ ) dried at 30 and $105^{\circ} \mathrm{C}$.

It can be seen here that the presence of Ettringite varies with the drying temperature (see Fig. 6). When drying the cement pastes at room temperature $\left(30^{\circ} \mathrm{C}\right)$, the volume content of Ettringite varies between 5 and 10\%, with a complex dependency on W/C. On the contrary, as soon as drying is carried out at high temperature $\left(105^{\circ} \mathrm{C}\right)$, the Ettringite content becomes close to $0 \%$. At $105^{\circ} \mathrm{C}$, we observe a small account of Ettringite (around $1.5 \%$ ) only for $\mathrm{W} / \mathrm{C}=0.2$. 


\section{Discussion and analysis}

\section{1. Effect of the drying temperature on the absorption}

When cement paste is dried at different temperatures, we observe that the measured water absorption increases with the drying temperature (see Fig. 1).

In this section, we first discard the role of a potential variation in residual water content, as an explanation of the differences in absorption observed as a function of temperature. We then discard the potential influence of an effect of the conditioning temperature on some micro-cracking, which would, in turn, modify the absorption irreversibly. We finally focus on relating the measured Ettringite dehydration to the increase in recycled aggregate absorption with temperature.

First, we need to verify that the water loss is not due to evaporation of remaining free water but finds its origin in the removal of some bound water.

After drying, some liquid water may remain in small pores. For higher temperatures, this residual water content might depend on drying temperature. For each temperature and humidity tested, we estimated the largest pore size at equilibrium with liquid water [31] using Kelvin's law [32]: $\ln (R H)=-\frac{2 \gamma V_{M}}{R T r_{e q}}$ where $\gamma$ is the surface tension at the Water/air interface $(0.072 \mathrm{~N} / \mathrm{m}), \mathrm{V}_{\mathrm{M}}$ is the molar volume of water $\left(18.10^{-6} \mathrm{~m}^{3} / \mathrm{mol}\right), \mathrm{R}$ is the ideal gas constant $(8.314 \mathrm{~J} / \mathrm{mol} / \mathrm{K}), \mathrm{T}$ is the temperature, $\mathrm{RH}$ is the relative humidity and $r_{e q}$ is the equilibrium pore radius. These values are reported in Table 2. 
Table 2

314 Experimental conditions (temperature and relative humidity) during the drying and 315 maximum capillary pore radius $\mathrm{r}_{\mathrm{eq}}$.

\begin{tabular}{lllllll}
\hline Temperature $\left({ }^{\circ} \mathrm{C}\right)$ & $\mathbf{2 2 . 5} \pm \mathbf{0 . 1}$ & $\mathbf{3 0 . 2} \pm \mathbf{1 . 0}$ & $\mathbf{4 5 . 3} \pm \mathbf{0 . 1}$ & $\mathbf{5 9 . 5} \pm \mathbf{0 . 1}$ & $\mathbf{7 5 . 0} \pm \mathbf{1 . 0}$ & $\mathbf{1 0 5} \pm \mathbf{1 . 5}$ \\
\hline $\mathrm{RH}(\%)$ & $6.2 \pm 0.4 \%$ & $22.7 \pm 2.6 \%$ & $7.0 \pm 1.6 \%$ & $2.0 \pm 0.1 \%$ & $0.9 \pm 0.1 \%$ & $0.6 \pm 0.1 \%$ \\
$\mathrm{r}_{\text {eq }}(\mathrm{nm})$ & $\mathbf{0 . 3 8}$ & $\mathbf{0 . 6 9}$ & 0.37 & 0.24 & $\mathbf{0 . 1 9}$ & 0.16 \\
\hline
\end{tabular}

316

317 For all drying conditions, the equilibrium pore size is of the order of some Angströms

318 (see in Table 2) around the value of one water molecule. For hardened cement paste, 319 the smallest pores are in the inter-layer of C-S-H, around one nanometer $(1-5 \mathrm{~nm})$ $320 \quad[30,33-35]$. Equilibrium pore sizes are smaller than the smallest pores of cement paste. 321 This suggests that all liquid water is evaporated at all studied temperatures.

322 Kelvin's law only gives an estimation. We validated experimentally that liquid water is 323 effectively absent. Indeed, drying conditions at $\mathrm{T}=22^{\circ} \mathrm{C}, \mathrm{RH}=6 \%$ are not directly 324 comparable to drying at $\mathrm{T}=105^{\circ} \mathrm{C}, \mathrm{RH}=0.6 \%$. For this purpose, we measured the mass 325 variation of our cement paste at $\mathrm{T}=22^{\circ} \mathrm{C}, \mathrm{RH}=0.6 \%$. A cured cement paste, initially 326 dried at $22^{\circ} \mathrm{C}$ and $\mathrm{HR}=6 \%$, was dried under vacuum with $\mathrm{RH}=0.6 \%$. Decreasing 327 RH from 6 to $0.6 \%$ leads to a mass difference of only $0.3 \%$, negligible compared to the 328 absorption variations with temperature (5-10\%) shown in Fig. 1. Thus, we consider that 329 all the liquid water is evaporated. We can therefore conclude that the difference in water 330 absorption measured subsequently is not the indirect consequence of Relative Humidity 331 variations but the direct consequence of temperature variations.

Mercury Intrusion Porosimetry confirms the increase in water absorption of the cement paste (see Fig. 1). Indeed, a significant difference in total porosity between drying at $30^{\circ} \mathrm{C}$ and $105^{\circ} \mathrm{C}$ was observed. This increase in water absorption with the drying temperature may be explained by two phenomena. First, during the drying, because of the creation of a temperature gradient, microcracking may take place in the hardened cement paste. This micro-cracking could explain the increase of water absorption with 
temperature $[19,36,37]$. The second phenomenon is a dehydration of the hydrates of the cement paste during drying [36-40] potentially causing a collapse of the gel structure. The pore size distributions for the different drying temperatures show that the increase of the drying temperature doubles the pore size in the cement paste (see Fig. 2). However, this result does not allow us to distinguish which phenomenon precisely is at the origin of this increase in pore size. Microcracking creates large pores as could dehydration.

However, we submitted a recycled aggregate to multiple drying/humidification steps and showed that the increase in absorption at $105^{\circ} \mathrm{C}$ is reversible (see Fig. 3). Indeed, after a drying at $105^{\circ} \mathrm{C}$ followed by a re-imbibition in water and, to finish, drying at $30^{\circ} \mathrm{C}$, the final measured water absorption was the same as for the reference dried directly at $30^{\circ} \mathrm{C}$. This reversible behavior favors the hypothesis of dehydration of hydrates of the cement paste during drying at $105^{\circ} \mathrm{C}$. Indeed, in the presence of microcracking, the water absorption of the recycled aggregate after the drying cycle would be equivalent to that initially measured during drying at $105^{\circ} \mathrm{C}$. We remind the reader here that our paste $\mathrm{W} / \mathrm{C}$ ratio of 0.5 does not support the idea of a potential self-healing of the micro-cracks during the re-imbibition phase [41,42]. Therefore, we suggest here that microcracking at $105^{\circ} \mathrm{C}$ is unlikely to create a significant increase in porosity and explain the crease in absorption with temperature.

We therefore focus now on relating the Ettringite dehydration shown in Fig. 4 to the measured absorption variations. In order to compare the observed increase in porosity with the total volume of Ettringite water, we calculated the volume fraction of water molecules in an Ettringite molecule $\left(\mathrm{C}_{6} \mathrm{~A} \$_{3} \mathrm{H}_{32}\right)$. Considering the molecular weight of each component of Ettringite, the mass proportion of water contained is $46 \%$. Then, considering that Ettringite density is $1.79[19,27,43]$, we estimate that $82 \%$ of the volume of Ettringite corresponds to the volume of the water molecules.

The volume content of Ettringite measured experimentally for our cement paste (W/C 0.5 ) is $9.5 \%$. Thus, the water contained in the Ettringite corresponds to a volume fraction of $8 \%$. We compare this result with the change of porosity between a drying 
at 30 and $105^{\circ} \mathrm{C}$. The porosity is computed from the water absorption with equation (2):

The difference in porosity measured between drying at $30^{\circ} \mathrm{C}$ and $105^{\circ} \mathrm{C}$ is also $8 \%$.

371 Thus, we suggest that the increase in porosity measured when the drying temperature is higher than the ambient temperature is due to the dehydration of Ettringite during drying.

The same kind of analysis is performed varying the W/C ratio. In Fig. 5 we observe that whatever the microstructure of the hardened cement paste, drying at high temperature has a very similar impact (on average equal to $5 \%$ ) on water absorption. On the other hand, the XRD results presented in Fig. 6 showed that drying at high temperature leads to dehydration of Ettringite, whatever the $\mathrm{W} / \mathrm{C}$ ratio of the cement paste. It also showed that the measured Ettringite content did have a complex dependency on the $\mathrm{W} / \mathrm{C}$ ratio of the cement paste.

382

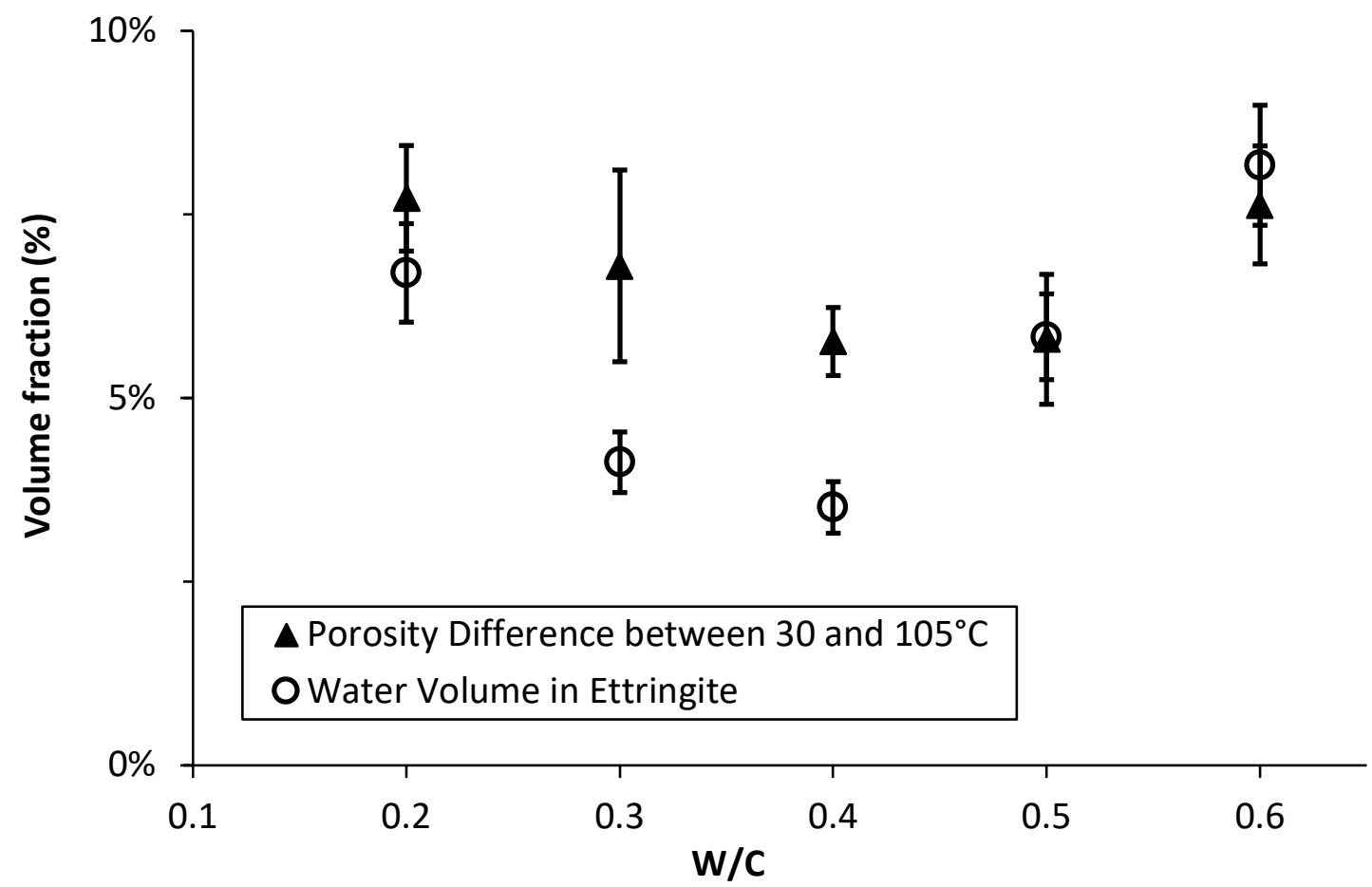

Fig. 7. Comparison of the volume of water present in the Ettringite for each cement paste (cement L) and the difference in porosity between 30 and $105^{\circ} \mathrm{C}$ as a function of the $\mathrm{W} / \mathrm{C}$ ratio. 
From the ettringite content in fig. 6 , we computed the volume of bound water and compared this volume and the difference of porosity between drying at 30 and $105^{\circ} \mathrm{C}$.

In Fig.7, we see that the bound water contents in Ettringite follow the same trend as the measured porosity difference between 30 and $105^{\circ} \mathrm{C}$.

It should be noted that the increase in temperature does not entirely dehydrate Ettringite. It should transform into Metaettringite $\left(12 \mathrm{H}_{2} \mathrm{O}\right)$ [20,44], which implies that some water molecules remain. Besides, it is likely that other hydrated phases, like Monosulfoaluminate, not observed in XRD, may also dehydrate at high temperatures. However, our results show that the contribution of Ettringite dehydration is of the same order of magnitude as the change of absorption.

To further support the above, we tested cement pastes with a water to binder radio equal to 0.5 prepared with different cements (cement LT and SPLC) and measured their water absorption at 30 and $105^{\circ} \mathrm{C}$. As we use cements with various $\mathrm{C}_{3} \mathrm{~A}$ content, which influences the amount of Ettringite formed, we assess the influence of the drying temperature on Ettringite content and variation of porosity/absorption. To compare the different cement pastes, we estimated the volume fraction of Ettringite for each cement, using the GEMS software (Gibbs Energy Minimization Software) [45-47] coupled with the CEMDATA database $[48,49]$. CEMDATA is a database developed specifically for the hydration of Portland cement-based systems. Thus, by knowing the chemical composition of each cement, we modeled the hydration of each of the cement pastes tested. Then, as for the previous results, we calculated the volume of water in Ettringite to the experimental difference of the porosity between 30 and $105^{\circ} \mathrm{C}$. 


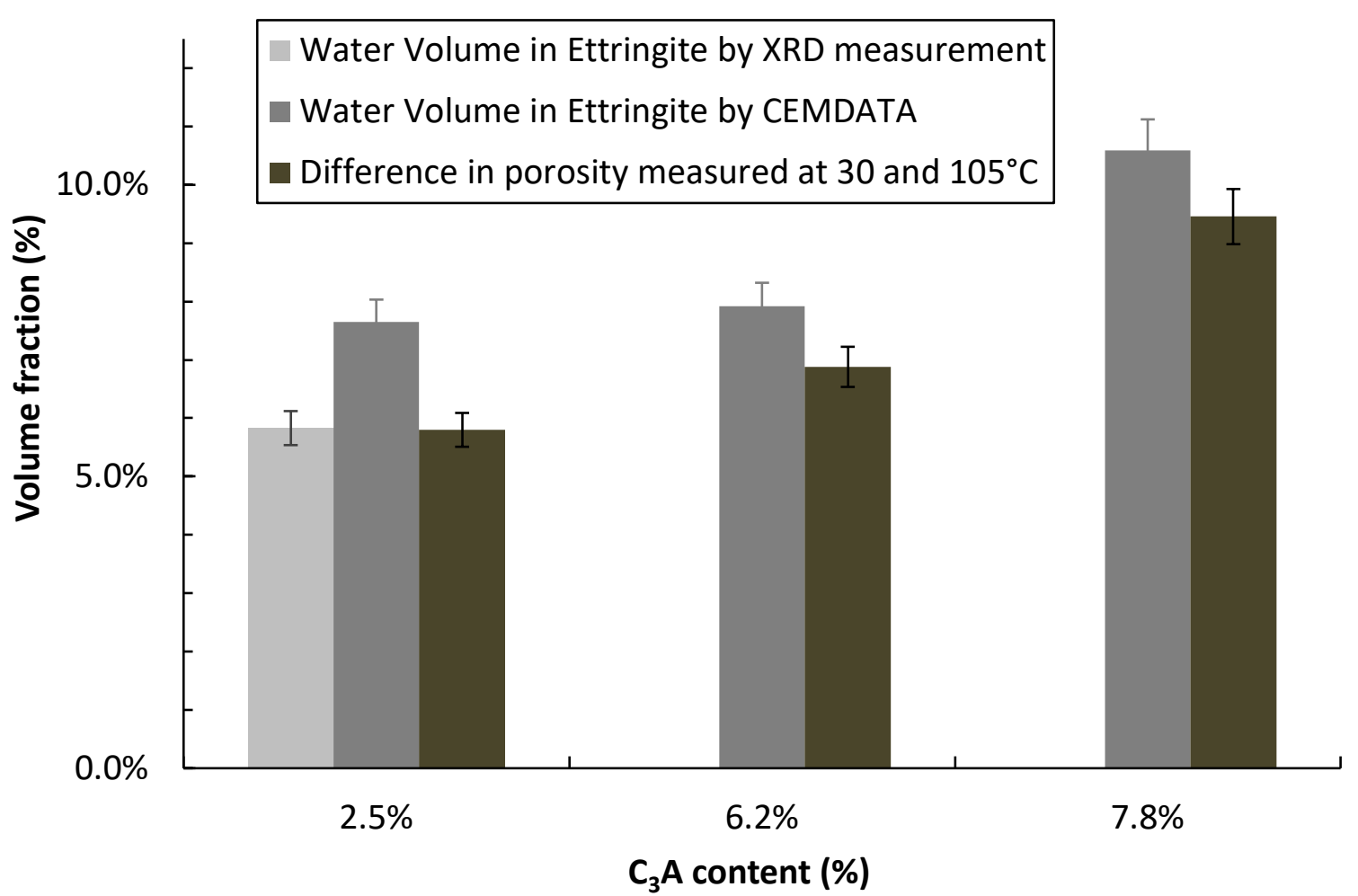

Fig. 8. Water volume in Ettringite (by XRD measurement and by CEMDATA) and porosity difference between $30^{\circ} \mathrm{C}$ and $105^{\circ} \mathrm{C}$, calculated by equation 2 , as a function of the $\mathrm{C}_{3} \mathrm{~A}$. Cement pastes at $\mathrm{W} / \mathrm{C}=0.5$ with cements $\mathrm{L}$, $\mathrm{LT}$ and SPLC.

As the $\mathrm{C}_{3} \mathrm{~A}$ content is increased by a factor of roughly three (from 2.5 to $7.8 \%$ ), the variation in porosity between 30 and $105^{\circ} \mathrm{C}$ roughly doubles (see Fig. 8). The Ettringite contents obtained by simulation follow a similar trend. For $\mathrm{C}_{3} \mathrm{~A}=2.5 \%$, the simulated Ettringite content is in very good agreement with the XRD measurement. Thus, the water volume contained in Ettringite, as estimated by thermodynamic simulation, is of the same order as the difference of porosity between the drying at 30 and $105^{\circ} \mathrm{C}$. From the above analysis, we suggest therefore that the increase in water absorption measured when the drying temperature is higher than ambient temperature is due to the dehydration of sulfo-aluminates (mostly Ettringite). 


\section{Practical consequences}

\section{1. Consequences on the measurement of water absorption}

As suggested by our results, an increase in the drying temperature of recycled aggregates leads to an overestimation of the actual water absorption of these aggregates, due to the creation of new porosities through sulfo-aluminates dehydration. Such an artefact will occur in all assessment procedures, where aggregates are dried at high temperatures before being tested. This would for instance be the case for pan-drying or oven drying.

On the other hand, on an industrial and job-site scale, aggregates are generally stored in silos or hoppers or simply in outdoor heaps. Moreover, in large quantities, thermal inertia is dominant compared to external temperature variations. Thus, even in cases where external temperature exceeds $30^{\circ} \mathrm{C}$ during daytime, these aggregates should not undergo dehydration before use. However, these aggregates, even if not affected by temperature variations from a microstructural point of view, are exposed to humidity variations and their consequences on water content. It is therefore necessary to dry them in order to measure both their water content and their total water absorption.

To solve the above issue, a straightforward approach would lie in drying recycled aggregates at room temperature $\left(\approx 30^{\circ} \mathrm{C}\right)$ and low relative humidity. However, drying at this temperature with strict control of relative humidity would result in a very long drying time (around a week), which is not suitable in an industrial context. It is therefore necessary to adapt the determination of absorption by considering the overestimation of the measured absorption value caused by drying at $105^{\circ} \mathrm{C}$. 


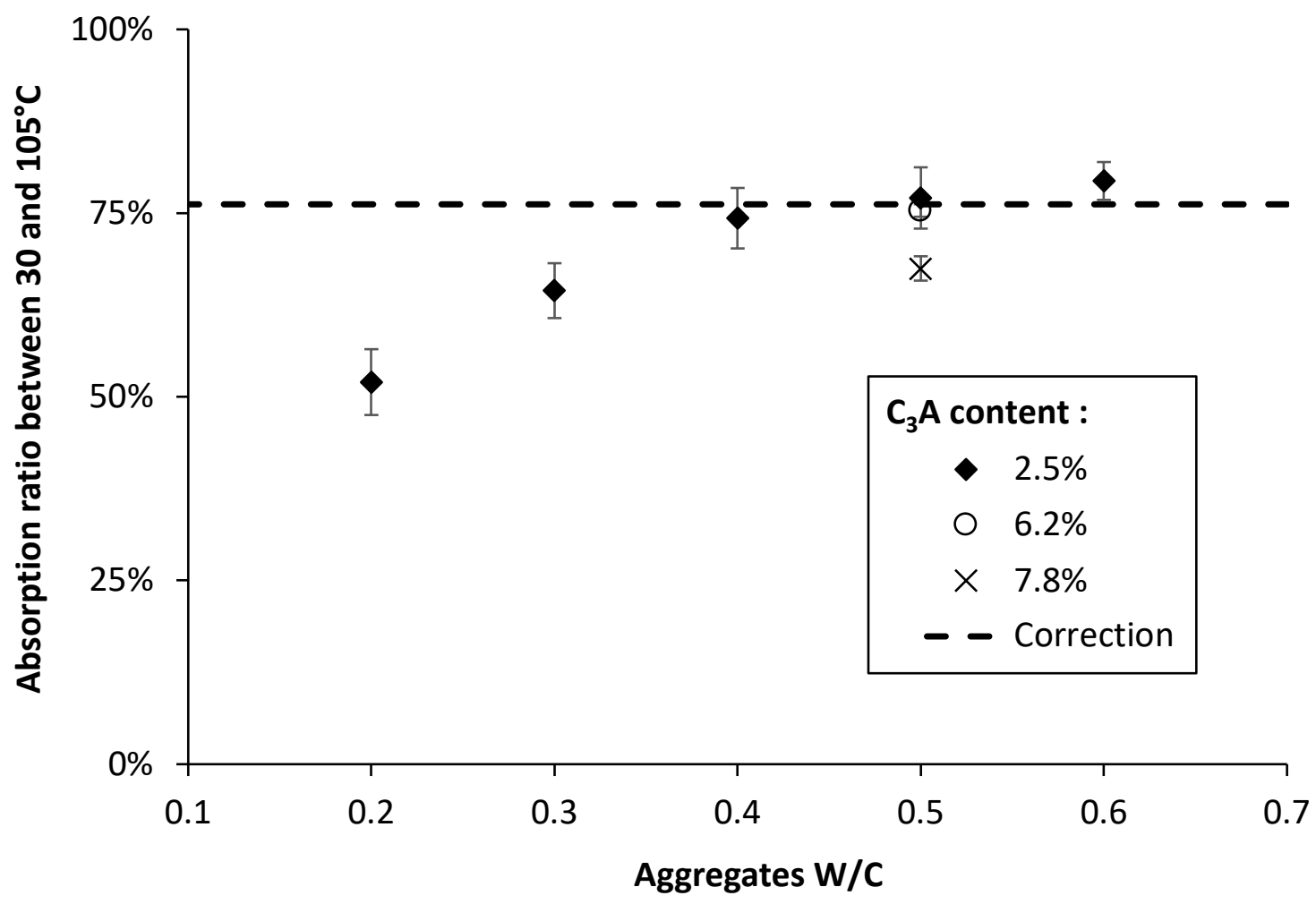

452

453

Fig. 9. Comparison of the overestimation of the water absorption caused by the drying at $105^{\circ} \mathrm{C}$ as a function of the $\mathrm{W} / \mathrm{C}$ ratio of the cement paste.

We gather in Fig. 9 the results obtained in this study, i.e. the ratio between the absorption measured at $30^{\circ} \mathrm{C}$ and that measured at $105^{\circ} \mathrm{C}$. We note that, in the range of standard concretes (W/C ratio between 0.4 and 0.6 ), the absorption ratio between 30 and $105{ }^{\circ} \mathrm{C}$ is constant and around $75 \%$.

A second-order feature in Fig. 9 is the role played by the $\mathrm{C}_{3} \mathrm{~A}$ content, which leads to a slight increase in the overestimation of the absorption value. We however consider here that, for typical $\mathrm{C}_{3} \mathrm{~A}$ content and typical $\mathrm{W} / \mathrm{C}$ ratio, the absorption ratio measured between 30 and $105^{\circ} \mathrm{C}$ is fairly constant and equal to $75 \%$ with a standard deviation of $3 \%$.

We define the absorption measuring the porous structure of our cementitious materials as the absorption at $30^{\circ} \mathrm{C}$ because this temperature does not alter the cement matrix. On the contrary, the drying at high temperature, in particular the usual preparation at $105^{\circ} \mathrm{C}$ degrades the hardened cement paste. Thus, this absorption at $105^{\circ} \mathrm{C}$ overestimates the void in the porous media. 
Based on our results, we propose to estimate the absorption due to the porous structure from the absorption measured at $105^{\circ} \mathrm{C}$ by: $A b s_{\text {poro }}=A b s_{105^{\circ} \mathrm{C}} \times 0.75$. The applicable range of $\mathrm{W} / \mathrm{C}$ is between 0.4 and 0.6 and the initial $\mathrm{C}_{3} \mathrm{~A}$ content of the cement is less than $6 \%$.

\section{2. Consequences on mix-design and mechanical properties of}

\section{concrete}

To emphasize the error in the mix design due to heat treatment in the water absorption measurement, we calculate the differences induced on the effective $\mathrm{w} / \mathrm{c}$ ratio and the expected mechanical strength. We consider here a cubic meter of an imaginary concrete formulated to reach an effective $\mathrm{W} / \mathrm{C}=0.5$ after aggregates absorption. This imaginary concrete contains $400 \mathrm{~kg}$ of cement, $700 \mathrm{~kg}$ of natural sand 0/4 mm (with negligible absorption) and $1000 \mathrm{~kg}$ of dry recycled aggregates $(>4 \mathrm{~mm})$. The water absorption of the recycled aggregates measured at $105^{\circ} \mathrm{C}$ is equal to $6.0 \%$ as in [50].

\section{What is expected to happen:}

The volume of water absorbed by the aggregates is expected from the measured absorption value to be $60 \mathrm{~L}$. The total water introduced in the mixer shall therefore be $260 \mathrm{~L}$ so that the effective water after absorption reaches $200 \mathrm{~L}$ and the $\mathrm{W} / \mathrm{C}$ ratio reaches 0.5 .

\section{What effectively happens:}

The absorption measurement with drying at $105^{\circ} \mathrm{C}$ overestimates the absorption of aggregates stored at a lower temperature. Indeed, the absorption due to porosity is $A b s_{\text {poro }}=6.0 \times 0.75=4.5 \%$. The volume of water absorbed by the aggregates is reduced to $45 \mathrm{~L}$ and $15 \mathrm{~L}$ of water are therefore not absorbed by aggregates, which results, in turn, into an effective water volume of $215 \mathrm{~L}$ instead of $200 \mathrm{~L}$ and therefore an increase in the $\mathrm{W} / \mathrm{C}$ of the concrete from 0.5 to 0.54 .

In order to roughly assess the impact of this increase in the effective $\mathrm{W} / \mathrm{C}$ ratio on the mechanical strength, we use the Bolomey formula [51], which predicts compressive strength at 28 days from the $\mathrm{W} / \mathrm{C}$ ratio. This relation suggests that a decrease in 
mechanical strength of the order of $10 \%$ could be expected.

Many studies report a decrease in mechanical strength of the order of $10 \%$ when substitution of natural aggregates by recycled aggregates is applied $[1,3,6,8]$. The question we raise here is whether the systematic decrease in mechanical strength reported in many papers is due to the inherent mechanical properties of recycled aggregates and their interfaces with the cement matrix or could simply be explained by the systematic increase in effective $\mathrm{W} / \mathrm{C}$ ratio induced by the high temperature artifact for absorption measurement showcased in the present study. However, if the water content is also determined at $105^{\circ} \mathrm{C}$, the water content of the aggregates will also be overestimated. Thus, the two errors compensate each other.

\section{Conclusions}

In this paper, we aimed at evaluating the impact of temperature during the drying step on the measurement of water absorption of recycled aggregates. We measured the water absorption of hardened cement pastes at various drying temperatures above ambient temperature of $30^{\circ} \mathrm{C}$. We specifically studied the impact of this drying on the pore distribution of these hardened cement pastes as well as on their mineralogical composition. A one-third increase in water absorption was observed between drying at room temperature $\left(30^{\circ} \mathrm{C}\right.$ and low relative humidity) and drying at $105^{\circ} \mathrm{C}$.

Our results and analyses suggest that this increase in water absorption with drying temperature increases finds its origin in the dehydration of Ettringite, which results in an increase in the pore size of the hardened cement paste and therefore in an increase in total porosity.

Thus, the drying step required to characterize the aggregates, in the case of recycled aggregates and depending on the temperature used, leads to a systematic overestimation of the water absorption. If the absorption and water content are measured with the same preparation protocol, there is no need for correction. However, this overestimation implies in turn a systematic error on the water correction to be applied to the mix design of recycled aggregate concretes. This results in more water being added than necessary 
to compensate for the volume of water absorbed by the aggregates, thus increasing the effective water to binder ratio of the concrete. This may, in turn, explain the typical decrease in measured mechanical strength when recycled aggregates substitute natural aggregates.

\section{Acknowledgement}

The authors would like to acknowledge the financial support of Chryso. The author would like to thank Myriam Duc for the XRD measurements, Othman Omikrine for the MIP measurements, Mickael Saillio for the ICP measurements, and Patrick Belin for the technical support.

\section{References}

[1] Z. Zhao, S. Remond, D. Damidot, W. Xu, Influence of fine recycled concrete aggregates on the properties of mortars, Constr. Build. Mater. 81 (2015) 179186. doi:10.1016/j.conbuildmat.2015.02.037.

[2] J. Naël-Redolfi, Absorption d' eau des granulats poreux: mesure et conséquences sur la formulation des mortiers et des bétons, $\mathrm{PhD}$ Thesis, Univ. Paris-Est. (2016).

[3] F. De Larrard, H. Colina, Concrete Recycling, CRC Press, 2019. doi:10.1201/9781351052825.

[4] S. Ismail, W.H. Kwan, M. Ramli, Mechanical strength and durability properties of concrete containing treated recycled concrete aggregates under different curing conditions, Constr. Build. Mater. 155 (2017) 296-306. doi:10.1016/j.conbuildmat.2017.08.076.

[5] A. Domingo-Cabo, C. Lázaro, F. López-Gayarre, M.A. Serrano-López, P. Serna, J.O. Castaño-Tabares, Creep and shrinkage of recycled aggregate concrete, Constr. Build. Mater. $23 \quad$ (2009) 2545-2553. doi:10.1016/j.conbuildmat.2009.02.018. 
[6] C. Medina, W. Zhu, T. Howind, M.I. Sánchez De Rojas, M. Frías, Influence of mixed recycled aggregate on the physical-mechanical properties of recycled concrete, J. Clean. Prod. 68 (2014) 216-225. doi:10.1016/j.jclepro.2014.01.002.

[7] M. Behera, S.K. Bhattacharyya, A.K. Minocha, R. Deoliya, S. Maiti, Recycled aggregate from $\mathrm{C} \& \mathrm{D}$ waste $\&$ its use in concrete - A breakthrough towards sustainability in construction sector: A review, Constr. Build. Mater. 68 (2014) 501-516. doi:10.1016/j.conbuildmat.2014.07.003.

[8] C. Zheng, C. Lou, G. Du, X. Li, Z. Liu, L. Li, Mechanical properties of recycled concrete with demolished waste concrete aggregate and clay brick aggregate, Results Phys. 9 (2018) 1317-1322. doi:10.1016/j.rinp.2018.04.061.

[9] W.H. Kwan, M. Ramli, K.J. Kam, M.Z. Sulieman, Influence of the amount of recycled coarse aggregate in concrete design and durability properties, Constr. Build. Mater. 26 (2012) 565-573. doi:10.1016/j.conbuildmat.2011.06.059.

[10] L. Evangelista, J. de Brito, Durability performance of concrete made with fine recycled concrete aggregates, Cem. Concr. Compos. 32 (2010) 9-14. doi:10.1016/j.cemconcomp.2009.09.005.

[11] M. Quattrone, B. Cazacliu, S.C. Angulo, E. Hamard, A. Cothenet, Measuring the water absorption of recycled aggregates, what is the best practice for concrete production?, Constr. Build. Mater. $123 \quad$ (2016) 690-703. doi:10.1016/j.conbuildmat.2016.07.019.

[12] Tests for mechanical and physical properties of aggregates. Determination of particle density and water absorption, EN 1097-6. (2013).

[13] J. Zhang, C. Shi, Y. Li, X. Pan, C.S. Poon, Z. Xie, Influence of carbonated recycled concrete aggregate on properties of cement mortar, Constr. Build. Mater. 98 (2015) 1-7. doi:10.1016/j.conbuildmat.2015.08.087.

[14] A. Djerbi Tegguer, Determining the water absorption of recycled aggregates utilizing hydrostatic weighing approach, Constr. Build. Mater. 27 (2012) 112116. doi:10.1016/j.conbuildmat.2011.08.018.

[15] T. LE, Influence de l'humidité des granulats de béton recyclé sur le comportement à l'état frais et durcissant des mortiers, Université de Lille, 2015. 
[16] V. Baroghel-bouny, Caractérisation microstructurale et hydrique des pâtes de ciment et des bétons ordinaires et à très hautes performances, Ecole Nationale des Ponts et Chaussées, 1994.

[17] I. Galan, H. Beltagui, M. García-Maté, F.P. Glasser, M.S. Imbabi, Impact of drying on pore structures in ettringite-rich cements, Cem. Concr. Res. 84 (2016) 85-94. doi:10.1016/j.cemconres.2016.03.003.

[18] Q. Zhou, F.P. Glasser, Thermal stability and decomposition mechanisms of Ettringite at $<120^{\circ} \mathrm{C}$, Cem. Concr. Res. 31 (2001) 1333-1339. doi:10.1016/S0008-8846(01)00558-0.

[19] S. Mantellato, M. Palacios, R.J. Flatt, Impact of sample preparation on the specific surface area of synthetic Ettringite, Cem. Concr. Res. 86 (2016) 20-28. doi:10.1016/j.cemconres.2016.04.005.

[20] L.G. Baquerizo, T. Matschei, K.L. Scrivener, Impact of water activity on the stability of Ettringite, Cem. Concr. Res. 79 (2016) 31-44. doi:10.1016/j.cemconres.2015.07.008.

[21] G. Renaudin, Y. Filinchuk, J. Neubauer, F. Goetz-Neunhoeffer, A comparative structural study of wet and dried Ettringite, Cem. Concr. Res. 40 (2010) 370375. doi:10.1016/j.cemconres.2009.11.002.

[22] M.E. Sosa, L. Carrizo, Y.A. Villagrán Zaccardi, C.J. Zega, Water Absorption of Fine Recycled Concrete Aggregates as an Indicator of Their Quality, IV Int. Conf. Prog. Recycl. Build Environ. (2018) 414-421.

[23] J. Naël-Redolfi, E. Keita, N. Roussel, Water absorption measurement of fine porous aggregates using an evaporative method: Experimental results and physical analysis, Cem. Concr. Res. (2018). doi:10.1016/j.cemconres.2017.11.003.

[24] M. Moranville, S. Kamali, E. Guillon, Physicochemical equilibria of cementbased materials in aggressive environments - experiment and modeling, 34 (2004) 1569-1578. doi:10.1016/j.cemconres.2004.04.033.

[25] J. Naël-Redolfi, E. Keita, N. Roussel, Water absorption measurement of fine porous aggregates using an evaporative method: Experimental results and 
physical analysis, Cem. Concr. Res. 104 (2017) 61-67. doi:10.1016/j.cemconres.2017.11.003.

[26] N. P18-459, Concrete - Testing hardened concrete - Testing porosity and density, (2010).

[27] K.L. Scrivener, R. Snellings, B. Lothenbach, A Practical Guide to Microstructural Analysis of Cementitious Materials, 2015. doi:10.1201/b19074.

[28] H. Ma, Mercury intrusion porosimetry in concrete technology: Tips in measurement, pore structure parameter acquisition and application, J. Porous Mater. 21 (2014) 207-215. doi:10.1007/s10934-013-9765-4.

[29] B. Lothenbach, T. Matschei, G. Möschner, F.P. Glasser, Thermodynamic modelling of the effect of temperature on the hydration and porosity of Portland cement, Cem. Concr. Res. 38 (2008) 1-18. doi:10.1016/j.cemconres.2007.08.017.

[30] K.L. Scrivener, A. Nonat, Hydration of cementitious materials, present and future, Cem. Concr. Res. 41 (2011) 651-665. doi:10.1016/j.cemconres.2011.03.026.

[31] M. Wu, B. Johannesson, M. Geiker, A study of the water vapor sorption isotherms of hardened cement pastes: Possible pore structure changes at low relative humidity and the impact of temperature on isotherms, Cem. Concr. Res. 56 (2014) 97-105. doi:10.1016/j.cemconres.2013.11.008.

[32] O. Coussy, Poromechanics, Wiley, 2004.

[33] A.M. Gajewicz, E. Gartner, K. Kang, P.J. McDonald, V. Yermakou, A 1H NMR relaxometry investigation of gel-pore drying shrinkage in cement pastes, Cem. Concr. Res. 86 (2016) 12-19. doi:10.1016/j.cemconres.2016.04.013.

[34] P.J. McDonald, V. Rodin, A. Valori, Characterisation of intra- and inter-C-S-H gel pore water in white cement based on an analysis of NMR signal amplitudes as a function of water content, Cem. Concr. Res. 40 (2010) 1656-1663. doi:10.1016/j.cemconres.2010.08.003.

[35] A.C.A. Muller, K.L. Scrivener, A reassessment of mercury intrusion porosimetry by comparison with1H NMR relaxometry, Cem. Concr. Res. 100 (2017) 350- 
360. doi:10.1016/j.cemconres.2017.05.024.

[36] H.F.W. Taylor, C. Famy, K.L. Scrivener, Delayed ettringite formation, Cem. Concr. Res. 31 (2001) 683-693. doi:10.1016/S0008-8846(01)00466-5.

[37] M. Castellote, C. Alonso, C. Andrade, X. Turrillas, J. Campo, Composition and microstructural changes of cement pastes upon heating, as studied by neutron diffraction, 34 (2004) 1633-1644. doi:10.1016/S0008-8846(03)00229-1.

[38] S. Mantellato, Flow loss in Superplasticized cement pastes, ETH Zurich, 2017. doi:https://doi.org/10.3929/ethz-b-000265510.

[39] P. Lalan, A. Dauzères, L. De Windt, D. Bartier, J. Sammaljärvi, J.D. Barnichon, I. Techer, V. Detilleux, Impact of a $70{ }^{\circ} \mathrm{c}$ temperature on an ordinary Portland cement paste/claystone interface: An in situ experiment, Cem. Concr. Res. 83 (2016) 164-178. doi:10.1016/j.cemconres.2016.02.001.

[40] S. Berger, Etude des potentialités des ciments sulfo-alumineux bélitique pour le conditionnement du zinc: de l'hydratation à la durabilité, Université de Lille, 2009.

[41] K. Tomczak, J. Jakubowski, The effects of age, cement content, and healing time on the self-healing ability of high-strength concrete, Constr. Build. Mater. 187 (2018) 149-159. doi:10.1016/j.conbuildmat.2018.07.176.

[42] B. Han, L. Zhang, J. Ou, Smart and multifunctional concrete toward sustainable infrastructures, Springer Nature, 2017. doi:10.1007/978-981-10-4349-9.

[43] A.C.A. Muller, K.L. Scrivener, A.M. Gajewicz, P.J. McDonald, Use of benchtop NMR to measure the density, composition and desorption isotherm of C-S$\mathrm{H}$ in cement paste, Microporous Mesoporous Mater. 178 (2013) 99-103. doi:10.1016/j.micromeso.2013.01.032.

[44] K. Ndiaye, M. Cyr, S. Ginestet, Durability and stability of an ettringite-based material for thermal energy storage at low temperature, Cem. Concr. Res. 99 (2017) 106-115. doi:10.1016/j.cemconres.2017.05.001.

[45] GEM Software, (n.d.). http://gems.web.psi.ch (accessed February 25, 2020).

[46] D.A. Kulik, T. Wagner, S. V. Dmytrieva, G. Kosakowski, F.F. Hingerl, K. V. Chudnenko, U.R. Berner, GEM-Selektor geochemical modeling package: 
Revised algorithm and GEMS3K numerical kernel for coupled simulation codes, Comput. Geosci. 17 (2013) 1-24. doi:10.1007/s10596-012-9310-6.

[47] T. Wagner, D.A. Kulik, F.F. Hingerl, S. V Dmytrieva, GEM-SELEKTOR GEOCHEMICAL MODELING PACKAGE: TSolMod LIBRARY AND DATA INTERFACE FOR MULTICOMPONENT PHASE MODELS, Can. Mineral. 50 (2012) 1173-1195. doi:10.3749/canmin.50.5.1173.

[48] EMPA, CEMDATA 18.1 Database, (2018).

[49] B. Lothenbach, D.A. Kulik, T. Matschei, M. Balonis, L. Baquerizo, B. Dilnesa, G.D. Miron, R.J. Myers, Cement and Concrete Research Cemdata18: A chemical thermodynamic database for hydrated Portland cements and alkaliactivated materials, Cem. Concr. Res. 115 (2019) 472-506. doi:10.1016/j.cemconres.2018.04.018.

[50] PN-RECYBETON, RECYBETON: Recyclage complet des bétons - Etude de faisabilité, IREX. (2011) 45.

[51] Z. Xue-bing, D. Shou-chang, D. Xu-hua, Q.I.N. Yin-hui, Experimental research on regression coefficients in recycled concrete Bolomey formula, J. Cent. South Univ. Technol. 14 (2007) 314-317. doi:10.1007/s11771. 